from 15 twin studies, sometimes with small sample sizes or often covering a large age range, provide heritabilities ranging from 0.14 to 0.83 . Data on explosive strength or power, often measured with standing broad jump or vertical jump, are less extensive but indicate significant genetic contributions to jumping performance. Functional strength or muscular endurance is mostly evaluated by tests such as bent arm hang, chin ups, sit ups, or leg lifts. In general, heritability estimates from sibling or family studies are lower than those from twin studies. Static strength and power tend to have higher heritabilities than muscular endurance. Gender differences are not always clear, but genes seem to play a more prominent role in male than in female strength determination

Data on time specific genetic and environmental regulation of strength performance variability are limited. During adolescence, tracking in static strength is largely determined by stable genes and stable unique environments during pre-adolescence. The genetic contribution to tracking in static strength is larger in boys than in girls. ${ }^{2}$ Heritability estimates for grip strength in men and women in the second half of life (45 years and older) vary between 0.14 and $0.52 .{ }^{3}{ }^{4}$ It seems reasonable to conclude that with the aging process and decline in muscle function, the genetic component of isometric strength is lower in older adults than it is during the growth process. No clear gender difference can be detected in any of the studies thus far reported.

\section{Genetic factors in trainability of strength}

Physical activity and specific, high resistance strength training are environmental factors that contribute or add to the observed differences in muscular strength and power between individuals both when young and in adulthood. The genotype $^{*}$ training interaction determines whether the observed heterogeneity in trainability is related to the genotype. In a 10 week high resistance strength training study of arm flexors in $25 \mathrm{MZ}$ and $16 \mathrm{DZ}$ male twins (22.4 \pm 3.7 years), responses in static and dynamic arm flexor strength and arm cross-sectional area were analysed using bivariate genetic models. Evidence for a genotype-environment interaction was found for the increase in one repetition maximum (IRM), static strength, and concentric flexion at $120 \%$ s.

\section{Gene powered? Gene hunting for muscular strength}

A yearly update is provided by the journal Medicine and Science in Sports and Exercise on the "Human gene map for performance and health related fitness phenotypes". In approach. The first method is localisation and identification by quantitative tion for the reliability of the measurements increased the heritabilities. Results 
the 2004 update, $^{6} 14$ association studies were included ( 12 in normal subjects and two in patients), of which seven were published in 2004. Allelic variations in several candidate genes showed significant associations with static or dynamic strength phenotypes. These allelic variations were observed in growth differentiation factor 8 or myostatin (GDF8 K153R), insulin-like growth factor 2 (IGF2 ApaI), ciliary neurotrophic factor (CNTF null), vitamin D receptor (VDR BsmI and FokI), type I collagen alphal (COLIAl Spl), angiotensin converting enzyme (ACE insertion/deletion), glucocortoid receptor (NRC3Cl ER22/23ER), and ciliary neurotrophic factor receptor (CNTFR C174) More recently, a stop codon polymorphism in the ACTN3 gene has been associated with power related sports ${ }^{7}$ and responses to strength training, ${ }^{8}$ as individuals carrying the XX genotype lack alpha-actinin-3 protein in the Z-disk of type II muscle fibres.

Linkage analysis was performed with polymorphic markers in genes of the myostatin pathway in the Leuven Genes for Muscular Strength Study, with (suggestive) linkage demonstrated for knee flexor and extensor strength with several markers in the myostatin pathway (D2S118, D6S1051, D11S4138, D13S1303, D12S1042, D12S85, and D $12 \mathrm{~S}^{10} 8^{10}$ ) but not with myostatin itself.

\section{CONCLUDING REMARKS}

Although strength phenotypes are under moderately strong to strong genetic control, there is still a long way to go before conclusive results concerning genetic polymorphisms associated or linked with these phenotypes can be presented. Each contributing gene will explain only a small portion of the observed interindividual differences. Most of the association studies have not yet been replicated in independent samples, only one group of researchers has performed linkage studies, and no genome-wide linkage or association analyses have yet been published. Additionally, when looking beyond the genomic sequence variations, alternative splicing induces "one gene-many proteins" relationships, and RNA interferences are now studied as interfering agents that can mimic loss of function phenotypes. Furthermore, the study of (heritable) epigenetic factors involved in strength related gene expression will probably increase exponentially in the future.

\section{ACKNOWLEDGEMENTS}

The authors thank all investigators of the Leuven Longitudinal Twin Study, the Twin and Training Study, and the Leuven Genes for Muscular Strength Study, upon whose original research this article is largely based. This leader is mainly derived from: Beunen G, Thomis M. Gene powered? Where to go from heritability $\left(\mathrm{h}^{2}\right)$ in muscle strength and power? Exerc Sport Sci Rev 2004;32:148-54.

Br J Sports Med 2006;40:822-823.

doi: $10.1136 /$ bjsm.2006.029116

\section{.......}

\section{Authors' affiliations}

G Beunen, M Thomis, Department of Biomedical Kinesiology, Faculty of Kinesiology and Rehabilitation Sciences, K.U. Leuven, Tervuursevest 101, B-3001 Leuven, Belgium
Correspondence to: Gaston Beunen, Department of Biomedical Kinesiology, Faculty of Kinesiology and Rehabilitation Sciences, K. U. Leuven, Tervuursevest 101, B-3001 Leuven, Belgium; gaston.beunen@faber.kuleuven.be

Accepted 20 July 2006

Competing interests: none declared

\section{REFERENCES}

1 Beunen G, Thomis M, Peeters M, et al. Genetics of strength and power characteristics in children and adolescents. Ped Exerc Sci 2003; 15:128-38.

2 Peeters MW, Thomis MA, Maes HHM, et al. Genetic and environmental determination of tracking in static strength during adolescence. J Appl Physiol 2005;99:1317-26.

3 Frederiksen H, Bathum L, Worm C, et al. ACE genotype and physical training effects: a randomized study among elderly Danes. Aging Clin Exp Res 2003; 15:284-91.

4 Tiainen K, Sipila, Alen M, et al. Heritability of maximal isometric muscle strength in older female twins. J Appl Physiol 2004;96:173-80.

5 Thomis MAI, Beunen GP, Maes HH, et al. Strength training: importance of genetic factors. Med Sci Sports Exerc 1998;30:724-31.

6 Wolfarth B, Bray MS, Hagberg JM, et al. The human gene map for performance and healthrelated fitness phenotypes: the 2004 update. Med Sci Sports Exerc 2005;35:881-903.

7 Yang N, MacArthur DG, Gulbin JP, et al. ACTN3 genotype is associated with human elite athletic performance. Am J Hum Genet 2003;73:627-31.

8 Clarkson PM, Devaney JM, Gordish-Dressman H, et al. ACTN3 genotype is associated with increases in muscle strength in response to resistance training in women. $J$ Appl Physiol 2005;99:154-63.

9 Huygens W, Thomis MA, Peeters MW, et al. Linkage of myostatin pathway genes with knee strength in humans. Physiol Genomics 2004; 17:264-70.

10 Huygens W, Thomis MAl, Peeters MWA, et al. Quantitative trait loci for human muscle strength: linkage analysis of myostatin pathway genes. Physiol Genomics 2005;22:390-7. 